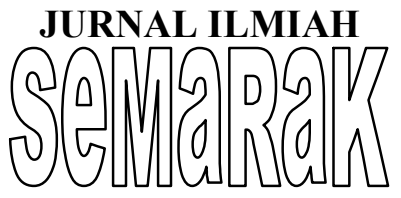

P-ISSN 2615-6849, E-ISSN 2622-3686

Jurnal Semarak,Vol. 1,No.3,Oktober 2018 , Hal (158-167)

@Prodi Manajemen Fakultas Ekonomi Universitas Pamulang

\title{
Dampak Pelemahan Kurs Rupiah, Aktifitas Dana Asing Dan Likuiditas Pasar Saham Terhadap Harga Saham Big Five Capitalization Pada Index LQ45 di Tahun 2018
}

\author{
Zulfitra, Muliahadi Tumanggor \& Ade Ratnasari \\ Staf Pengajar Fakultas Ekonomi Universitas Pamulang \\ Email: zulfitra.dosen@gmail.com, dosen00871@unpam.ac.id
}

\begin{abstract}
ABSTRAK
Fenomena pelemahan kurs rupiah, aktifitas dana asing dan likuditas pada pasar saham Indonesia ditahun 2018 menjadi perhatian peneliti. Alasan ini merupakan hal yang menarik bagi peneliti untuk mengkaji fenomena tersebut, yang diharapkan dapat memberikan kontribusi bagi ilmu pengetahuan khususnya dalam pengambilan keputusan investasi portofolio saham. Tujuan dari penelitian secara empiris untuk membuktikan adanya pengaruh pelemahan kurs rupiah, aktifitas dana asing dan likuiditas pasar saham terhadap harga saham big five capitalization pada Index LQ45 di tahun 2018 baik secara parsial maupun simultan. Peneliti menggunakan sampel 5 emiten dengan kapitalisasi pasar terbesar dari Index Saham LQ45 Bursa Efek Indonesia. Jumlah observasi dalam penelitian sebanyak 590, dengan 118 data time series harian dari tanggal 2 Mei 2018 sampai 31 Oktober 2018. Metode penelitian menggunakan regresi data panel dengan Random Effect Model. Hasilnya menunjukkan bahwa pada saham big five capitalization Index LQ45 terdapat pengaruh signifikan secara parsial kurs rupiah dan aktifitas dana asing terhadap harga saham. Dan secara simultan kurs rupiah, aktifitas dana asing dan likuiditas pasar saham mempengaruhi harga saham big five capitalization Index LQ45
\end{abstract}

\section{Kata kunci: Kurs Rupiah, Aktifitas Dana Asing, Likuditas, Harga Saham, LQ45, Regresi Data Panel}

\begin{abstract}
The phenomenon of the weakening of the rupiah exchange rate, the activity of foreign funds and liquidity in the Indonesian stock market in 2018 is of concern to researchers. This reason is an interesting thing for researchers to study this phenomenon, which is expected to contribute to science, especially in stock portfolio investment decision making. The purpose of empirical research is to prove the influence of the weakening of the rupiah exchange rate, foreign fund activity and stock market liquidity on the big five capitalization stock price in the LQ45 index in 2018 both partially and simultaneously. The researcher uses a sample of 5 issuers with the largest market capitalization of the Indonesia Stock Exchange LQ45 Stock Index. The number of observations in the study was 590, with 118 daily time series data from May 2, 2018 to October 31, 2018. The research method used panel data regression with the Random Effect Model. The results show that in the big five capitalization LQ45 Index there is a significant influence partially on the rupiah exchange rate and the activity of foreign funds on stock prices. And simultaneously the rupiah exchange rate, foreign funds activities and market liquidity affect the big five capitalization stock price of the LQ45 Index.
\end{abstract}

Keywords: Rupiah Exchange Rate, Activity Of Foreign Funds, Liquidity, Stock Price, LQ45, Data Panel Regression.

\section{PENDAHULUAN}

\section{A. Latar Belakang}

Investasi saham menarik untuk dipelajari, karena kita dapat memperoleh keuntungan berupa capital gain dan mendapatkan dividen per share yang diberikan oleh perusahaan. Banyak sekali faktor yang digunakan dalam keputusan membeli atau menjual saham pada harga yang tepat. Pada riset-riset terdahulu telah dibahas mengenai faktor-faktor fundamental makroekonomi dan 
JURNAL

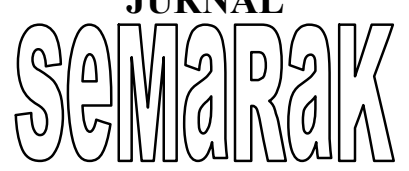

@Prodi Manajemen Fakultas Ekonomi Universitas Pamulang

mikroekonomi yang dijelaskan oleh Ross, Stephen A (1976) dalam Arbitrage Pricing Theory. Selain itu juga faktor teknikal yang sejak lama telah diperkenalkan oleh Cowles, Alfred (1933) dengan pola pergerakan saham bull market, bear market dan doubtfull market. Fenomena yang menarik yang berkaitan dengan teori Arbitrage Pricing Theory yaitu pelemahan kurs rupiah per US dollar di tahun 2018, dimana selama periode amatan penelitian terlihat peningkatan kurs rupiah sejak bulan mei sampai oktober 2018. Tentunya hal ini akan berdampak menurunnya harga saham, seperti pada beberapa Negara di dunia dan tidak hanya di Indonesia. Hubungan antara kurs mata uang suatu Negara terhadap harga saham telah dijelaskan dalam penelitian yang dilakukan oleh Altin, Hakan (2014), Aydemir, O \& Demirhan, Erdal. (2009), Morales, Lucia. (2007), Gatsi, et al (2016) dan penelitian Phylaktis, K., Ravazzolo, F (2005). Data Kurs Rupiah selama periode amatan penelitian dapat dilihat dalam grafik di bawah ini:

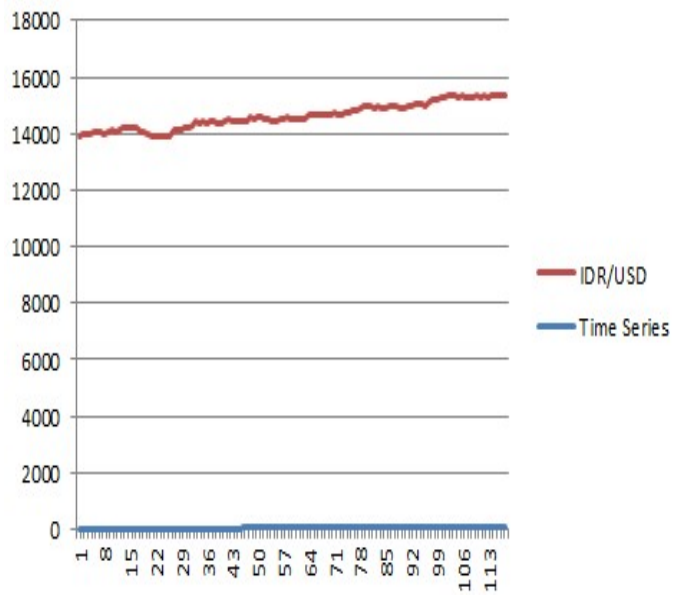

Gambar 1. Grafik Kurs Rupiah per US Dollar 2 Mei-31 Oktober 2018 (sumber BI)

Hal lain yang menjadi perhatian peneliti adalah aktifitas dana asing, berupa keluar masuknya dana asing pada masingmasing portofolio saham. Pada penelitian terdahulu telah dijelaskan oleh Bansal, Anand \& Pasricha, J.S (2009), Gonçalves, Walter., \& Eid, William (2017), Hsu, Chun-Pin (2013), Kim, Jeong-Bon., \& Yi, Cheong. H (2015), Tas, Oktay., Tan, Selin Duz (2016). Penelitian terdahulu dari para ahli diatas menjelaskan bahwa masuknya dana asing ke dalam portofolio saham masing-masing emiten akan berdampak positif terhadap peningkatan harga saham.

Peneliti mengambil sampel pada 5 emiten index LQ45 dengan market kapitalisasi terbesar, yaitu PT Bank Central Asia Tbk, PT Bank Rakyat Indonesia (Persero) Tbk, PT Hanjaya Mandala Sampoerna Tbk, PT Telekomunikasi Indonesia (Persero) Tbk dan PT Bank Mandiri (Persero) Tbk. 
JURNAL

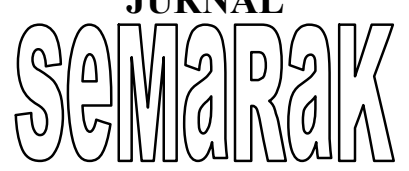

P-ISSN 2615-6849 E-ISSN 2622-3686

Semarak,Vol. 1, No.3,Oktober 2018, Hal (1-20)

@Prodi Manajemen Fakultas Ekonomi Universitas Pamulang
Aktifitas dana asing yang masuk dan keluar pada masing-masing saham sampel penelitian dapat dilihat pada grafik berikut ini :

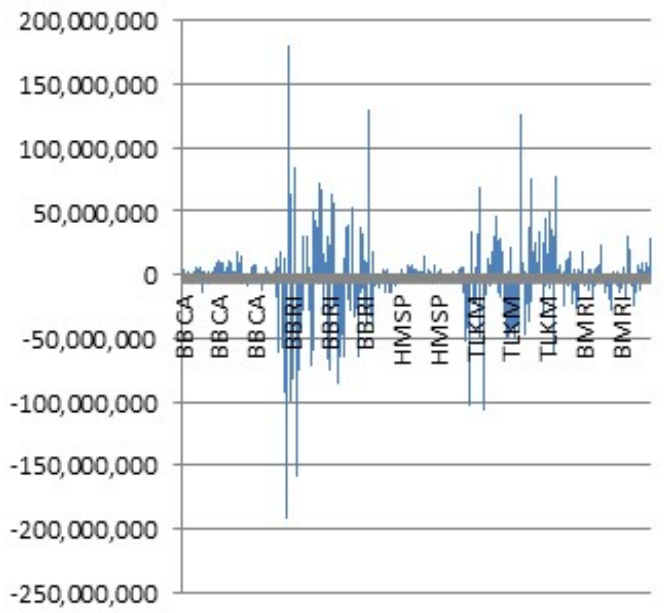

Gambar 2. Grafik aktifitas dana asing pada masingmasing saham (sumber BEI)

Faktor lain yang menjadi penelitian peneliti adalah likuditas saham pada masing-masing emiten yang akan berdampak terhadap harga saham. Hal ini dijelaskan dalam penelitian terdahulu oleh Abidin, et al (2016), Basci, et al (1996) dan Ciner, C (2003). Likuditas menjelaskan banyaknya aktifitas jual beli saham pada masing-masing pasar saham emiten, dapat dilihat dari volume transaksi saham. Adapun fenomena likuiditas saham dijelaskan pada pada grafik berikut ini:

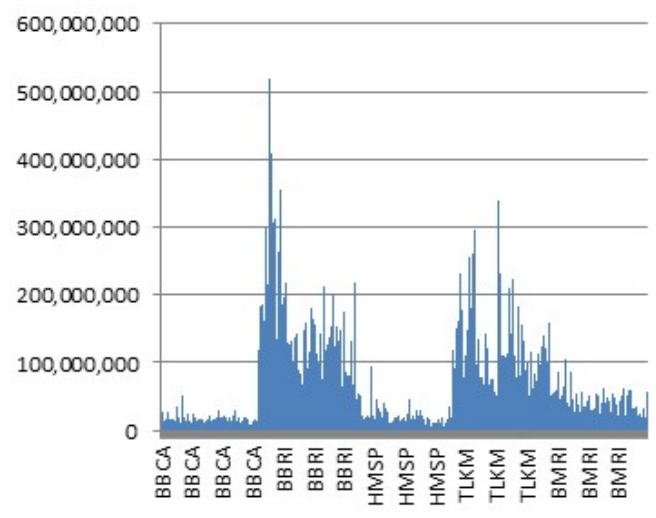

Gambar 2. Grafik likuditas pasar saham pada masing-masing saham (sumber BEI)

Harga saham masing-masing emiten yang diteliti selama periode amatan mengalami fluktuasi. Peneliti menduga bahwa masing-masing faktor yang telah dijelaskan diatas akan mempengaruhi harga saham, sehingga perlu dikaji hubungan masing-masing faktor tersebut diatas ke dalam penelitian ini. Adapun fenomena pergerakan harga saham disajikan dalam grafik di bawah ini:

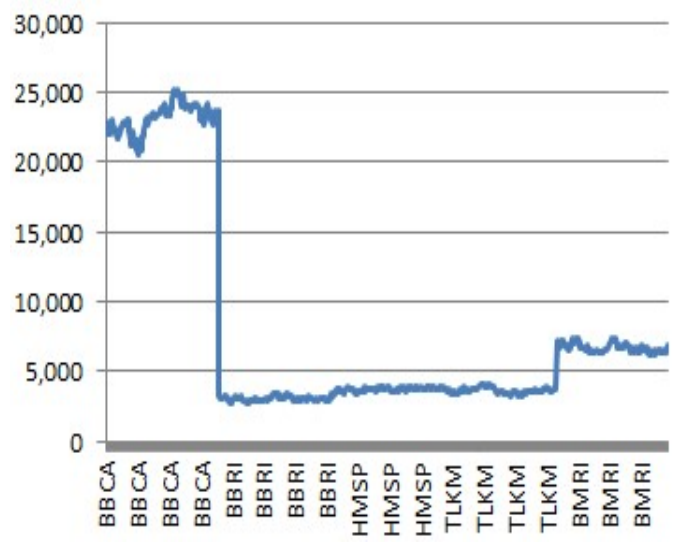

Gambar 2. Grafik harga saham pada masing-masing saham (sumber BEI) 
JURNAL

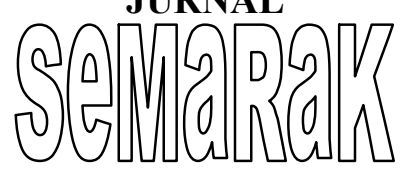

Semarak,Vol. 1, No.3,Oktober 2018, Hal (1-20)

@Prodi Manajemen Fakultas Ekonomi Universitas Pamulang

\section{B. Perumusan Masalah}

Apakah kurs rupiah, aktifitas dana asing dan likuiditas pasar saham berpengaruh terhadap harga saham big five capitalization pada index LQ45 di tahun 2018, baik secara parsial maupun simultan?

\section{Tujuan Penelitian}

Tujuan penelitian secara empiris untuk membuktikan adanya pengaruh kurs rupiah, aktifitas dana asing dan likuiditas pasar saham terhadap harga saham big five capitalization pada index LQ45 di tahun 2018 baik secara parsial maupun simultan.

\section{TINJAUAN PUSTAKA}

\section{A. Arbitrage Pricing Theory (APT)}

Teori ini pertama kali diperkenalkan Ross, Stephen di tahun 1976 yang saat ini dikenal dengan Arbitrage Pricing Theory atau disebut juga dengan Teori APT. Kemudian Roll, Richard., \& Ross, Stephen. A. (1980) menemukan bukti empiris tes untuk arbitrage theory of asset pricing. Dengan menggunakan data individu ekuitas selama periode 19621972, paling sedikit tiga dan mungkin empat faktor "harga" yang ditemukan menghasilkan return proses. Teori ini didukung estimasi dari expected return berdasarkan estimasi loading faktor dan variable-variabel seperti standar deviasi masing-masing, meskipun masing-masing variable sangat berkorelasi (secara sederhana) dengan expected return, tidak ada kekuatan tambahan penjelasan loading factor. Selanjutnya Chen, Roll dan Ross mengembangkan teori ini di tahun 1986, hasil penelitiannya menemukan variable makroekonomi yang memberikan dampak sistematik terhadap pasar saham (return saham), seperti suku bunga, inflasi, produksi industri dan obligasi (Chen, 1986).

\section{B. Pengaruh Kurs terhadap Harga Saham}

Penelitian terdahulu yang mengkaji hubungan kurs terhadap harga saham dijelaskan dalam Altin, Hakan. (2014) dimana sampel penelitian diambil dari Istanbul Stock Exchange (ISE) di Negara Turki, dengan menggunakan 3252 observasi pada periode 2001 sampai 2012. Hasil dari penelitiannya menunjukkan bahwa Kurs Turkish Lira berpengaruh negatif signifikan terhadap harga saham di Istanbul Stock Exchange (ISE) Turki. Penelitian berikutnya menjelaskan hal yang sama oleh Aydemir, O \& Demirhan, Erdal. (2009), sample penelitian menggunakan 100 emiten di ambil dari Istanbul Stock Exchange (ISE) selama tahun 2001 sampai dengan 2008. Hasil dari penelitiannya membuktikan bahwa Kurs Turkish Lira mempunya pengaruh yang negatif signifikan terhadap harga 
JURNAL

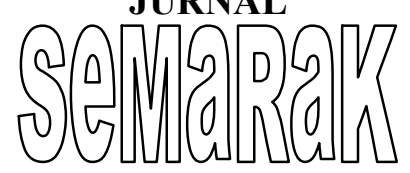

P-ISSN 2615-6849 E-ISSN 2622-3686

Semarak,Vol. 1, No.3,Oktober 2018, Hal (1-20)

@Prodi Manajemen Fakultas Ekonomi Universitas Pamulang saham. Gatsi et al (2016) menemukan

bukti Kurs Cedi (Ghana's currency) memiliki pengaruh yang negatif signifikan terhadap harga saham, Gatsi mengambil sample penelitian dari Ghana Stock Exchange tahun 1998-2011. Morales, Lucia (2007) melakukan riset pada setiap kurs dan harga saham di negara-negara Czech Republic, Hungary, Poland dan Slovakia, selama tahun 1999 sampai dengan tahun 2006, observasi penelitian berjumlah 1964, hasil penelitiannya membuktikan bahwa di masing-masing negara Kurs mempunyai pengaruh negative dan signifikan terhadap harga saham. Penelitian berikutnya oleh Phylaktis, K., \& Ravazzolo, F (2005) yang menunjukkan hasil bahwa Kurs berpengaruh negatif signifikan terhadap harga saham. Phylaktus meelakukan 400 observasi pada negara-negara di wilayah Pasific Basin selama tahun 1980 sampai dengan tahun 1998.

\section{Pengaruh aktifitas dana asing terhadap harga saham}

$\begin{array}{rrrr}\text { Aktifitas } & \text { dana } & \text { asing } & \text { dapat } \\ \text { ditunjukkan melalui } & \text { foreign } & \text { value }\end{array}$
maupun foreign volume. Beberapa penelitian yang mengkaji hubungan dana asing terhadap harga saham dijelaskan dalam penelitian Bansal, A \& Pasricha, J.S (2009) dimana dana asing berpengaruh positif terhadap harga saham.
Bansal mengambil sampel dari 30 saham Blue Chip SENSEX Index, pada pasar saham Bombay Stock Exchange tahun 2001 sampai 2004. Selanjutnya Gonçalves, W., \& Eid, W.(2017) dalam penelitiannya menjelaskan bahwa dana asing berpengaruh positif terhadap harga saham, sample diambil dari Brazilian Stock Market BM \& F-Bovespa data, dengan jumlah observasi lebih dari 3000 pada periode pengamatan 2002 sampai 2015. Kemudian dalam penelitan yang dilakukan Hsu, Chun-Pin (2013) menjelaskan adanya pengaruh positif dana asing terhadap harga saham, dengan menggunakan sample 100 emiten di pasar saham Taiwan Stock Exchange (TWSE) dengan jumlah observasi sebanyak 2730 tahun 2001-2011. Penelitian Kim Kim, Jeong-Bon., \& Yi, Cheong. H (2015) pada pasar saham Korea Stock Exchange dengan jumlah observasi sebanyak 4508 dari 10 tahun 1998 sampai 2007 menunjukkan adanya pengaruh yang positif signifikan dana asing terhadap harga saham. penelitian berikutnya dilakukan oleh Tas, Oktay., Tan, Selin Duz (2016) dimana sample penelitian diambil dari Borsa Istanbul 100 Index, dengan jumlah observasi sebanyak 10 pada periode 2009 sampai 2014. Hasil penelitiannya menunjukkan bahwa dana asing berpengaruh positif terhadap harga saham. 
Semarak,Vol. 1, No.3,Oktober 2018, Hal (1-20)

@ Prodi Manajemen Fakultas Ekonomi Universitas Pamulang

\section{Pengaruh likuiditas transaksi terhadap} Harga Saham

Likuditas transaksi saham dapat dilihat dari volume perdagangan maupun frekuensi perdagangan. Beberapa penelitian terdahulu yang menjelaskan hubungan likuditas dengan harga saham dijelaskan dalam penelitian Basci, et al (1996) dengan mengambil sampel sebanyak 29 sekuritas dengan jumlah observasi 166, data diperoleh dari pasar saham Istanbul Securities Exchange dari tahun 1988 sampai 1991. Hasil penelitian Basci menunjukkan likuiditas saham mempunya pengaruh yang positif signifikan terhadap harga saham. Bukti selanjutnya dijelaskan oleh Ciner, Cetin. (2003) hasil penelitiannya menunjukkan bahwa likuiditas saham berpengaruh positif terhadap harga saham. sample penelitiannya diambil dari Index S\&P 600 dan Nouveau Marche (NM) Index pada pasar saham Paris Stock Exchange, dengan jumlah observasi penelitian pada masing-masing index sebanyak 1684 dan 928. Data penelitian diambil dari tahun 1995 sampai 2002. Penelitian Abidin et al (2016) menunjukkan hasil bahwa likuiditas berpengaruh negative terhadap harga saham pada periode 2012 sampai 2015, sampel diambil dari 17 emiten index IDX30 di Bursa Efek Indonesia.

\section{E. Hipotesis Penelitian}

Berdasarkan kajian penelitian terdahulu maka peneliti merumuskan hipotesis penelitian yaitu terdapat pengaruh kurs rupiah, aktifitas dana asing dan likuiditas pasar saham terhadap harga saham big five capitalization pada index LQ45 di tahun 2018 baik secara parsial maupun simultan.

\section{METODE PENELITIAN}

Penelitian menggunakan metode analisis regresi data panel, dengan menguji 3 model yaitu: Common Effect (Pooled EGLS) Model, Fixed Effect Model dan Random Effect Model. Pengujian model menggunakan Redundant Fixed Effects Tests, Hausman Test dan Lagrange Multiplier Tests. Penelitian menggunakan data cross section sebanyak 5 emiten index LQ45 dengan market kapitalisasi terbesar, yaitu PT Bank Central Asia Tbk, PT Bank Rakyat Indonesia (Persero) Tbk, PT Hanjaya Mandala Sampoerna Tbk, PT Telekomunikasi Indonesia (Persero) Tbk dan PT Bank Mandiri (Persero) Tbk. Data time series yang digunakan sebanyak 118. Jumlah observasi penelitian sebanyak 590 .

\section{HASIL DAN PEMBAHASAN}

Data hasil penelitian diolah dengan menggunakan Eviews 9, mengasilkan 3 model penelitian yaitu Common Effect Model, Fixed Effect Model dan Random Effect Model. Uji pemilihan model dengan menggunakan Uji Chow Test (Redundant Fixed 
JURNAL

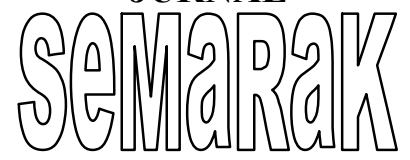

Semarak,Vol. 1, No.3,Oktober 2018, Hal (1-20)

@Prodi Manajemen Fakultas Ekonomi Universitas Pamulang

Effects Tests), Hausman Test dan LM

Test

Redundant Fixed Effects Tests

Pool: Untitled

Test cross-section fixed effects

\begin{tabular}{lccc}
\hline \hline Effects Test & Statistic & d.f. & Prob. \\
\hline \hline Cross-section F & 15468.931525 & $(4,582)$ & 0.0000 \\
\hline \hline
\end{tabular}

Hasil pengujian menunjukkan Probability value signifikan, maka model yang dipilih adalah Fixed Effect Model.

Correlated Random Effects - Hausman

Test

Pool: Untitled

Test cross-section random effects

\begin{tabular}{lrrr}
\hline \hline & $\begin{array}{l}\text { Chi-Sq. } \\
\text { Statistic }\end{array}$ & $\begin{array}{r}\text { Chi-Sq. } \\
\text { d.f. }\end{array}$ & Prob. \\
\hline \hline $\begin{array}{l}\text { Cross-section } \\
\text { random }\end{array}$ & 0.000000 & 3 & 1.0000 \\
\hline \hline
\end{tabular}

Hasil pengujian menunjukkan menunjukkan Probality Value tidak signifikan, maka model yang dipilih adalah Random Effect Model.

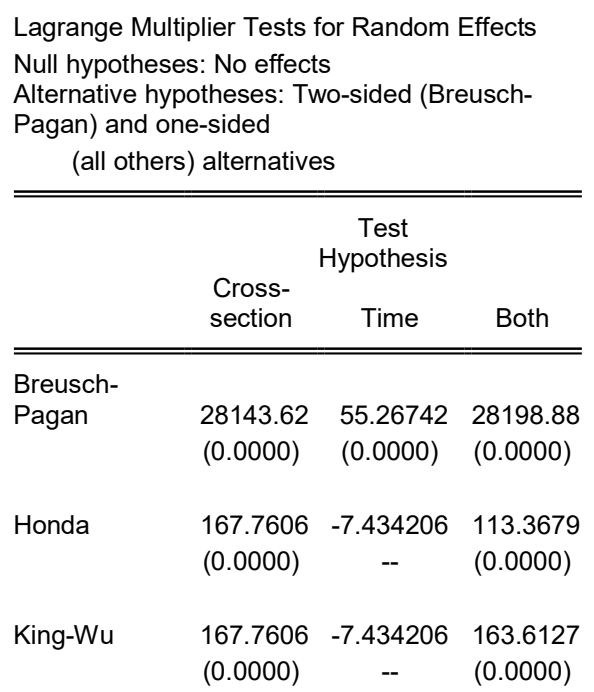

Standardized

Honda $\quad 210.5401 \quad-7.354131 \quad 120.2371$

(0.0000) - $\quad-\quad(0.0000)$

Standardized

King-Wu $\quad 210.5401 \quad-7.354131 \quad 201.2088$

(0.0000) -- $\quad(0.0000)$

Gourierioux, et

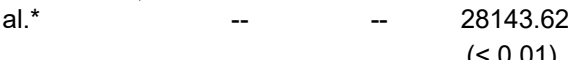

$<0.01)$

*Mixed chi-square asymptotic critical values:

$\begin{array}{rr}1 \% & 7.289 \\ 5 \% & 4.321 \\ 10 \% & 2.952\end{array}$

Hasil pengujian menunjukkan

Probability Value Breusch-Pagan

signfikan, maka model yang dipilih adalah

Random Effect Model

Hasil pengujian model:

\begin{tabular}{ll} 
Pengujian & Hasil Pengujian \\
\hline Chow Test & Fixed Effect \\
Hausmant Test & Random Effect \\
LM Test & Random Effect
\end{tabular}

Berdasarkan pengujian diatas, maka model yang dipilih untuk mengestimasi model regresi data panel.dalam penelitian ini adalah Random Effect Model. Berikut ini peneliti menyajikan Random Effect Model

Dependent Variable: PRICE?

Method: Pooled EGLS (Cross-section random effects)

Date: 09/14/18 Time: 09:18

Sample: 00010118

Included observations: 118

Cross-sections included: 5

Total pool (balanced) observations: 590

Swamy and Arora estimator of component variances

Variable Coefficient Std. Error t-Statistic Prob.


JURNAL

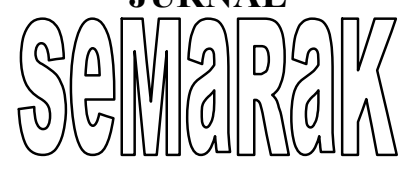

Semarak,Vol. 1, No.3,Oktober 2018, Hal (1-20)

@Prodi Manajemen Fakultas Ekonomi Universitas Pamulang

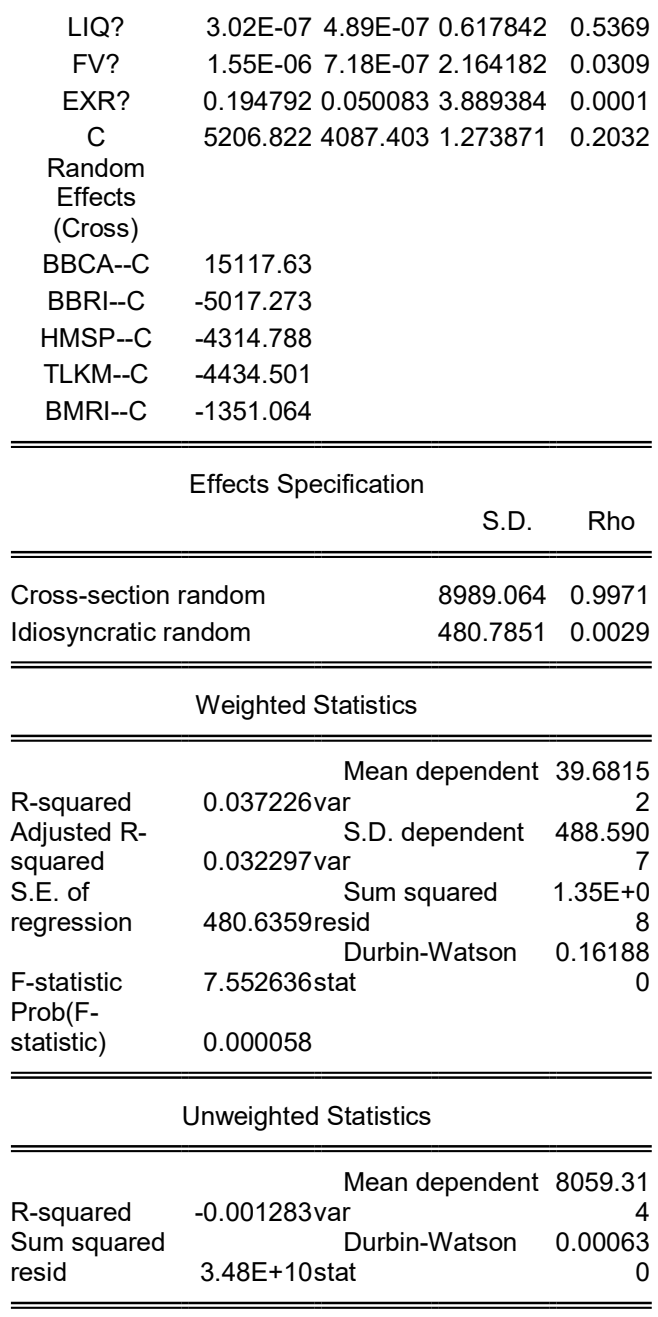

Dalam model diatas dapat dilihat bahwa secara parsial likuditas pasar saham (LIQ) tidak berpengaruh terhadap harga saham, dengan $\mathrm{p}$ value 0.5369 . kemudian secara parsial aktifitas dana asing (FV) berpengaruh positif signifikan terhadap harga saham, dengan $\mathrm{p}$ value 0.0309 . kemudian kurs rupiah (EXR) berpengaruh positif signifikan terhadap harga saham dengan $\mathrm{p}$ value 0.0001 . Secara simultan likuditas pasar saham (LIQ), aktifitas dana asing (FV) dan kurs rupiah (EXR) berpengaruh positif signifikan terhadap harga saham, dengan $p$ value 0.000058 .

Model regresi data panel penelitian disajikan sebagai berikut:

Estimation Command:

LS(CX=R) PRICE? LIQ? FV? EXR? C

Estimation Equations:

PRICEBBCA $=\mathrm{C}(5)+\mathrm{C}(1) * \mathrm{LIQBBCA}+$ $\mathrm{C}(2) * \mathrm{FVBBCA}+\mathrm{C}(3) * \mathrm{EXRBBCA}+\mathrm{C}(4)$

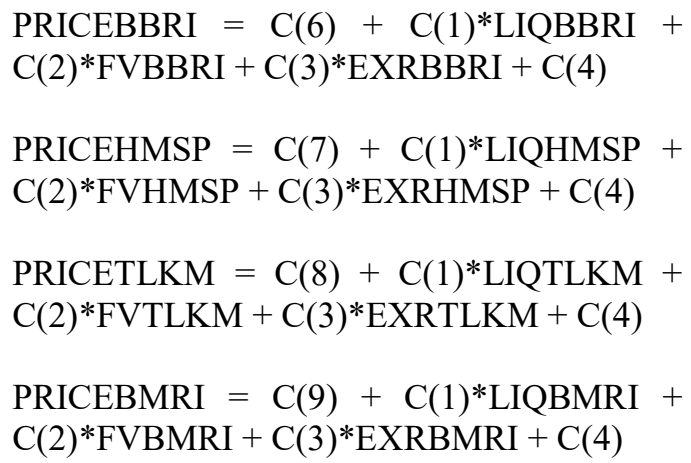

Substituted Coefficients:

$\begin{array}{ll}================ \\ \text { PRICEBBCA }=\quad 15117.6259872 & + \\ \text { 3.02295055227e-07*LIQBBCA } & + \\ 1.55446476009 \mathrm{e}-06 * \text { FVBBCA } & + \\ 0.194791603775 * \text { EXRBBCA } & +\end{array}$

5206.8221666

PRICEBBRI $=-5017.27300113+$

3.02295055227e-07*LIQBBRI +

$1.55446476009 \mathrm{e}-06 * \mathrm{FVBBRI}+$

$0.194791603775 *$ EXRBBRI +5206.8221666

PRICEHMSP $=-4314.78827691+$ 3.02295055227e-07*LIQHMSP + $1.55446476009 \mathrm{e}-06 *$ FVHMSP $\quad+$ $0.194791603775 *$ EXRHMSP + 5206.8221666

PRICETLKM $=-4434.50052148+$
$3.02295055227 \mathrm{e}-07 *$ LIQTLKM
Page 165




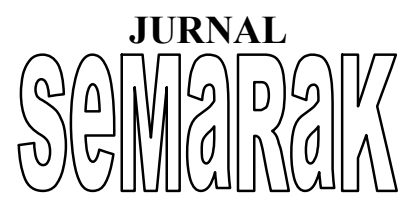

P-ISSN 2615-6849 E-ISSN 2622-3686

Semarak,Vol. 1, No.3,Oktober 2018, Hal (1-20)

@Prodi Manajemen Fakultas Ekonomi Universitas Pamulang

$1.55446476009 \mathrm{e}-06 *$ FVTLKM

$0.194791603775 *$ EXRTLKM

5206.8221666

PRICEBMRI = -1351.06418771 +

3.02295055227e-07*LIQBMRI

$1.55446476009 \mathrm{e}-06 * \mathrm{FVBMRI}$

$0.194791603775 * \mathrm{EXRBMRI}$

5206.8221666

\section{KESIMPULAN DAN SARAN}

A. Kesimpulan

Secara parsial kurs rupiah dan aktifitas dana asing berpengaruh terhadap harga saham, namun secara parsial likuditas pasar saham tidak berpengaruh terhadap harga saham. Sedangkan secara simultan kurs rupiah, aktifitas dana asing dan likuiditas pasar saham mempengaruhi harga saham big five capitalization Index LQ45.

\section{B. Saran}

Investor perlu mencermati terjadinya perubahan kurs rupiah dan aktifitas dana asing pada portofolio dari masing-masing emiten karena memberikan dampak terhadap pergerakan harga saham.

\section{DAFTAR PUSTAKA}

Abidin, Sugeng., Suhadak., \& Hidayat, Raden Rustam. (2016). Pengaruh FaktorFaktor Teknikal Terhadap Harga Saham (Studi Pada Harga Saham IDX30 di Bursa Efek Indonesia Periode Tahun 2012-2015). Jurnal Administrasi Bisnis (JAB), Vol. 37 No.1, Agustus 2016.

Altin, Hakan. (2014). Stock Price And Exchange Rate: The Case Of Bist 100. European Scientific Journal, June 2014 Edition Vol.10, No.16 ISSN: $+\quad 1857$ - 7881 (Print) e - ISSN 1857-

+7431 .

Aydemir, O \& Demirhan, Erdal. (2009). The Relationship Between Stock Prices And Exchange Rates Evidence From Turkey. International Research Journal of Finance and Economics. 1 (23). 207-215.

Bansal, Anand \& Pasricha, J.s. (2009). Foreign Institutional Investor's Impact On Stock Prices In India. Journal of Academic Research in Economics. 1. 174-182.

Basci, Erdem., Suheyla Ozyildirim., Kursat Aydogan. (1996). A Note On PriceVolume Dynamics In An Emerging Stock Market. Elsevier, Journal of Banking \& Finance 20 (1996) 389400.

Chen, Nai-Fu; Richard Roll; Stephen A. Ross. (1986). Economic Forces and the Stock Market. The Journal of Business, Vol. 59, No.3 (Jul., 1986), 383-403.

Ciner, Cetin. (2003). Dynamic Linkages Between Trading Volume and Price Movements: Evidence for Small Firm Stocks. The Journal of Entrepreneurial Finance, Volume 8 Issue 1 Spring 2003.

Cowles, Alfred 3rd. (1933). Can Stock Market Forecasters Forecast? Econometrica, Vol. 1, No. 3 (Jul., 1933), pp. 309-324.

Gatsi, John Gartchie., Appiah, Michael Owusu., Wesseh Jr, Presley K. (2016). Exchange Rates and Stock Prices in Ghana. Journal of Applied Business and Economics Vol. 18(3) 2016.

Gonçalves, Walter., \& Eid, William. (2017). Sophistication And Price Impact Of Foreign Investors In The Brazilian Stock Market. Emerging Markets Review, 33, 102-139. 


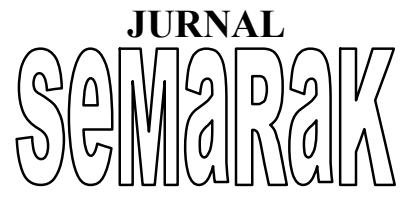

Kim, Jeong-Bon., \& Yi, Cheong. H. (2015).
Foreign
Versus
Domestic

Institutional Investors In Emerging Markets: Who Contributes More To Firm-Specific Information Flow? China Journal of Accounting Research, 8(1), 1-23.

Morales, Lucia. (2007). The Dynamic Relationship Between Stock Prices And Exchange Rates: Evidence From Four Transition Economies. Paperpresented to the Asociación Española de Economía y Finanzas (AEEFI), X Décimas Jornadas de Economía International, June 20-22, Madrid, Spain, 2007.

Phylaktis, Kate., Ravazzolo, Fabiola. (2005). Stock prices and exchange rate dynamics. Journal of International Money and Finance 24 (2005) 10311053.

Roll, Richard., \& Ross, Stephen. A. (1980). An Empirical Investigation of the Arbitrage Pricing Theory. The Journal of Finance, 35(5), 1073.

Ross, Stephen A. (1976). The Arbitrage Theory of Capital Asset Pricing. Journal Of Economic Theory 13, 341-360 (1976).

Tas, Oktay., Tan, Selin Duz. (2016). Corporate Governance, Foreign Ownership And Stock Price Synchronicity: Evidence From Borsa Istanbul. Journal of Economics, Finance and Accounting-(JEFA), Volume: 3, Issue: 2. ISSN: 21486697. 